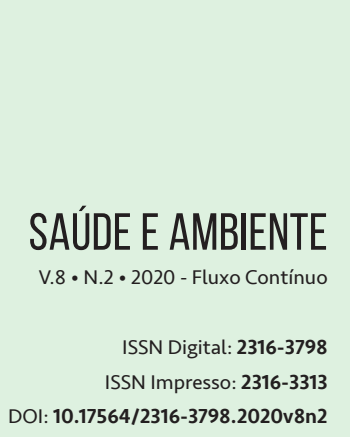

\section{ANÁLISE DO TEOR DE FORMALDEÍDO LIVRE EM ALISANTES CAPILARES}

\section{ANALYSIS OF FREE FORMALDEHYDE CONTENT IN HAIR STRAIGHTENERS}

\section{ANÁLISIS DEL CONTENIDO DE FORMALDEHÍDO LIBRE EN LOS ALISADORES DE CABELLO}

Ábia Rodrigues ${ }^{1}$

Fernanda Siqueira Souza ${ }^{2}$ Janice Botelho Souza Hamm ${ }^{3}$

\section{RESUMO}

O formol é um ingrediente comum utilizado em alisantes capilares. Cabelereiros estão expostos ao perigo deste produto químico, por seu uso indevido e elevada concentração nas escovas progressivas. Pela análise qualitativa e quantitativa este estudo tem como objetivo identificar os teores de formaldeído livre em seis amostras de produtos capilares de quatro empresas diferentes, utilizando o reagente de Schiff e por titulação. Dos seis produtos analisados cinco apresentaram concentrações de formaldeído acima dos valores permitido conforme resolução No 29 da ANVISA, na qual somente uma amostra apresentava dentro dos valores de referência conforme descrito no rótulo, ficando evidente a importância da avaliação e conhecimento do produto nos salões de beleza antes da aplicação, tanto para o profissional como para o usuário.

\section{PALAVRAS-CHAVE}




\section{ABSTRACT}

Formaldehyde is a common ingredient used in hair straighteners to obtain the perfect smooth. Hair stylists are exposed to the danger of this chemical due to its misuse and high concentration in the progressive brushes. Through qualitative and quantitative analysis, this study aims to identify free formaldehyde levels in six samples of hair products in four different companies, using Schiff's reagent and by titration. Five products analyzed showed evidence of formaldehyde above the number allowed according to ANVISA Resolution No. 29, which only one sample had the formaldehyde described on the label. It is evident the importance of evaluation and knowledge of the product in beauty salons before application for both the professional and the user.

\section{KEYWORDS}

Hair, Methanal, ANVISA.

\section{RESUMEN}

El formaldehído es un ingrediente común utilizado en planchas para el cabello para obtener la suavidad perfecta. Los estilistas están expuestos al peligro de este químico debido a su mal uso y alta concentración en los cepillos progresivos. Mediante un análisis cualitativo y cuantitativo, este estudio tiene como objetivo identificar los niveles de formaldehído libre en seis muestras de productos para el cabello en cuatro compañías diferentes, utilizando el reactivo de Schiff y mediante valoración. Cinco productos analizados mostraron evidencia de formaldehído por encima del número permitido de acuerdo con la Resolución ANVISA No. 29, en la cual solo una muestra tenía el formaldehído descrito en la etiqueta. Es evidente la importancia de la evaluación y el conocimiento del producto en los salones de belleza antes de la aplicación tanto para el profesional como para el usuario.

\section{PALABRAS CLAVE}

Cabello, Metanal, ANVISA 


\section{INTRODUÇ̧̃̃o}

Para a maioria das mulheres, o cabelo é muito importante, pois contribui para a identidade individual. Normalmente, é utilizado para expressar a beleza, atratividade e individualidade. Ter o cabelo manejável que desafia a humanidade é um desejo antigo entre as mulheres de vários grupos étnicos. Isto fica evidente pela multiplicidade de alisamentos e suavizações técnicas que são usados em todo o mundo (WEATHERSBY; MCMICHAEL, 2012).

O formaldeído $\left(\mathrm{CH}_{2} \mathrm{O}\right)$ ou aldeído fórmico, denominado metanal pela IUPAC, em temperatura ambiente é um gás incolor, com odor forte e característico. 0 metanal em solução apresenta densidade de $1,084 \mathrm{~g} \cdot \mathrm{cm}^{-3}$, massa molecular igual a $30,03 \mathrm{~g}$, ponto de fusão a $-92^{\circ} \mathrm{C}$ e de ponto de ebulição a $96^{\circ} \mathrm{C}$.

Formaldeído como é conhecido popularmente, é um produto químico muito comum utilizado na formulação de alisantes capilares, pois tem a ação de alterar a estrutura do fio. Em condições normais de temperatura e o contato direto com grandes concentrações torna-se perigoso à saúde humana, pois causa problemas respiratórios, sensibilidade cutânea, sensibilidade imunológica, mutagênese e carcinogênese (INCA, 2018). O problema abrange também, a má aplicação dos alisantes capilares, a falta de conhecimento do teor de formaldeído aplicado e os efeitos colaterais.

A Agência Nacional de Vigilância Sanitária (ANVISA) proíbe o uso de formaldeído para a finalidade de alisante capilar, entretanto, o composto pode ser utilizado com concentração máxima de $0,2 \%$ para a função de conservante, conforme RDC 162/01, e como agente endurecedor de unhas com concentração máxima permitida de até 0,5\%, conforme RDC 215/05 (ANVISA, 2013). Os alisantes registrados na ANVISA só são aceitos depois que a empresa comprovar por uma série de testes e documentos de que o produto alisante não causa danos à saúde e que em sua formulação não haja formaldeído, nem a liberação dele, quando aquecido.

0 processo de alisamento dá-se por duas formas: Calor e Alisamento químico, sendo que o processo de desnaturação da proteína é obtido pelo calor, na utilização de chapinhas ou secadores de cabelo, este efeito é temporário pois o cabelo quando exposto a umidade retorna a sua aparência normal. Em alisamentos químicos utiliza-se formulações alcalinas que permitem o efeito liso de maneira permanente, mesmo quando os cabelos são expostos a umidade. As camadas do córtex e medula, são quebradas temporariamente, permitindo reconstruí-la na forma desejada.

De acordo com a ANVISA, em 2019, após uma fiscalização em municípios de 21 estados e do Distrito Federal, os formulários encaminhados pelos fiscais sanitários relataram que, para $22,4 \%$ dos que perceberam irregularidades, a adição ou manipulação pode ter sido feita pelo profissional cabeleireiro. Já para 15,9\% desses fiscais, as duas situações ocorrem: tanto o produto é fabricado com um teor de formol acima do permitido, como o produto é adicionado ao cosmético. Entretanto, é difícil esconder o cheiro forte que o formaldeído possui no produto, uma vez que esta substância é volátil.

Neste contexto, o objetivo do presente trabalho foi analisar amostras de alisantes capilares contidas no mercado, quantificando o teor de formaldeído livre em sua composição. 0 presente trabalho alerta para os riscos causados aos profissionais e ao consumidor, além de verificar se os produtos cosméticos que possuem característica alisante, estão de acordo com as normas preconizadas pela ANVISA. 


\section{MATERIAIS E MÉTODOS}

O presente trabalho foi desenvolvido em três etapas, conforme mostra a Figura 1: (I) Coleta das amostras e caracterização; (II) Avaliação do teor de formaldeído nas amostras e cálculos; (III) Comparação dos resultados com a legislação e com a literatura.

Figura 1 - Fluxograma da metodologia em etapas

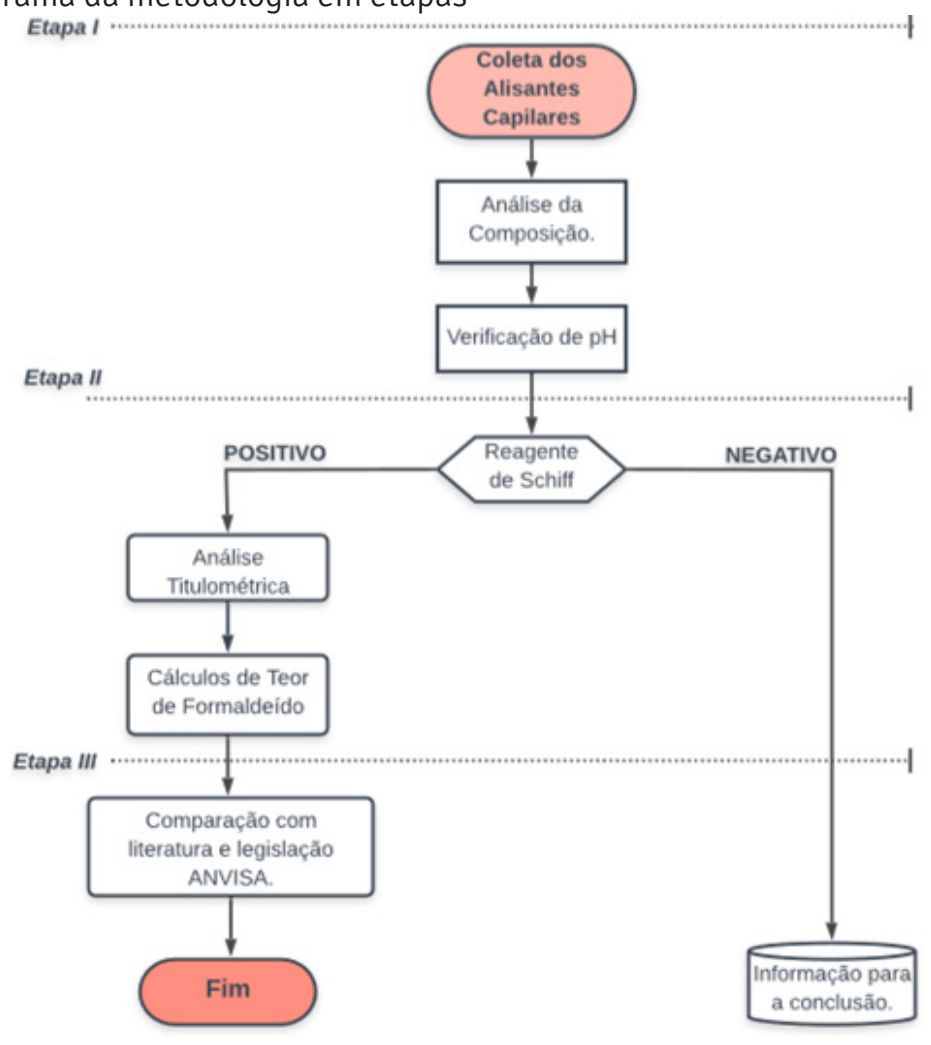

Fonte: Autores

\subsection{ETAPA 1: COLETA DAS AMOSTRAS E CARACTERIZACÃA}

A coleta das amostras foi realizada em cidades da região metropolitana do Rio Grande do Sul, sendo coletadas de três lugares diferentes, onde 4 amostras foram coletadas em salões de beleza e as outras duas na empresa fabricante de produtos cosméticos, totalizando 6 amostras. As amostras foram coletadas em frascos plásticos, com aproximadamente $100 \mathrm{~g}$, armazenadas longe do calor e umidade. Realizou-se uma análise qualitativa na composição das amostras para verificação do com- 
ponente formaldeído (descrita na etapa 2). Após verificou-se o valor de $\mathrm{pH}$ das amostras dos alisantes capilares puros, por meio de um pHmetro Digital (Gehaka PG1800).

A escolha delas deu-se por disponibilidade dos locais que cederam as amostras para este trabalho.

\subsection{ETAPA 2: AVALIAÇÃO DO TEOR DE FORMALDÉ́dO NAS AMOSTRAS}

Foram analisados os seis diferentes alisantes capilares, seguindo o método do reagente de Schiff para verificação de formaldeído livre nas amostras. Após o resultado, as amostras foram preparadas para a titulação e cálculo do teor de formaldeído presente no produto (SALATINE, 2011).

Para Identificação do formaldeído livre nas amostras de alisantes capilares utilizou-se a metodologia descrita no Guia de Controle de Qualidade de Produtos Cosméticos. No procedimento experimental a análise do teor de formaldeído livre foi proposta pela AOAC International, por método de titulação, com utilização do indicador Azul de Bromotimol. (SCARABELOT; MICHELS, 2007).

\subsubsection{MÉTODO DE SCHIFF: VERIFICAÇ̃̃O DE FORMALDÉ́DO LIVRE NA AMOSTRA}

Aqueceu-se a água até $100^{\circ} \mathrm{C}$ sob um agitador magnético com aquecimento (Multitec) adicionou-se $1 \mathrm{~mL}$ de fucsina (New Prov). Após atingir a temperatura de $60^{\circ} \mathrm{C}$, acrescentou-se $2 \mathrm{~g}$ de metabissulfito de sódio (Alpha Química) sob agitação constante até total dissolução do soluto. Quando a solução atingiu temperatura ambiente, acrescentou-se $10 \mathrm{~mL}$ de ácido clorídrico (Dinâmica), armazenando o reagente em um frasco branco leitoso com tampa lacre, envolto de papel alumínio para não haver contato com a luz (ANVISA, 2007a).

$\mathrm{Na}$ balança (BEL- S2202h) pesou-se $2 \mathrm{~g}$ de cada amostra de alisante capilar em béqueres. Acrescentou-se 2 gotas de ácido sulfúrico $1 \mathrm{M}$ (Dinâmica) com $2 \mathrm{~mL}$ do reagente de Schiff, sob leve agitação. Transcorrido cinco minutos, o formaldeído livre combinado com o meio sulfúrico na presença do reagente de Schiffindicou coloração rosa a malva (ANVISA, 2007b).

\subsubsection{MÉTODO DE TITULAÇ̃̃o: ANÁLISE DA PORCENTAGEM DE FORMALDÉ́DO LIVRE}

Em um balão volumétrico de $100 \mathrm{ml}$ pipetou-se $50 \mathrm{~mL}$ de hidróxido de sódio $1 \mathrm{M}$ (Dinâmica), $50 \mathrm{~mL}$ de peróxido de hidrogênio (Neon) $3 \%$ e $3 \mathrm{~g}$ do alisante capilar. Inseriu-se os balões volumétricos com os meniscos ajustados, em banho maria (Quimis/Q215M2) na temperatura de $50^{\circ} \mathrm{C}$ pelo tempo de 5 minutos. Transcorrido o tempo retirou-se do banho e deixou-se atingir temperatura ambiente. Coletou-se $10 \mathrm{~mL}$ da solução do balão e adicionou-se 3 gotas do indicador azul de bromotimol (Dinâmica). Titulou-se com ácido clorídrico $1 \mathrm{M}$ até a viragem de azul para amarelo.

0 procedimento foi realizado em triplicata nas cinco amostras de alisantes capilares que apresentaram coloração rosa/malva na identificação de formaldeído livre pelo método de Schiff.

Os cálculos do teor de formaldeído nas amostras foram realizados conforme o trabalho de Salatine (2011), de acordo com a estequiometria das reações e resultados da titulação. A Figura 2 apresenta um fluxograma com as etapas dos cálculos realizados para o presente trabalho. 
Figura 2 - Cálculos do Teor de Formaldeído

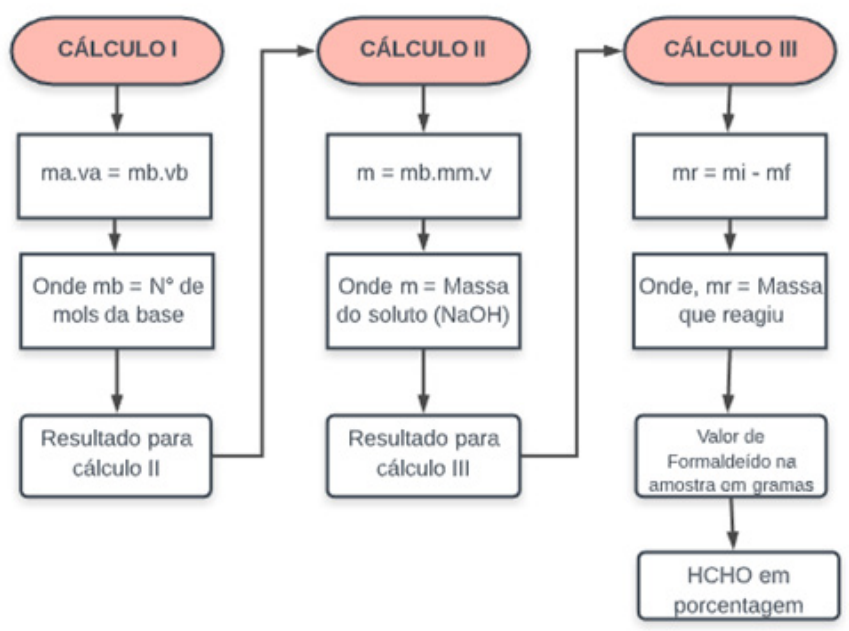

Fonte: Salatine (2011)

Onde, as variáveis dos cálculos seguem no Quadro 1.

Quadro 1 - Variáveis dos cálculos I, II, III.

\begin{tabular}{|c|c|c|c|c|c|}
\hline \multirow{4}{*}{ Cálculo I } & $\begin{array}{c}\mathrm{m}_{\mathrm{a}} \text { Número de mols } \\
\text { (Ácido) }\end{array}$ & \multirow{4}{*}{ Cálculo II } & $\begin{array}{l}\text { m Massa do } \\
\text { soluto }(\mathrm{g})\end{array}$ & \multirow{4}{*}{ Cálculo III } & $\mathrm{m}_{\mathrm{i}}$ Massa Inicial \\
\hline & v volume (Ácido) & & $\begin{array}{c}\text { mm Massa Molar } \\
(\mathrm{g} / \mathrm{mol})\end{array}$ & & $\mathrm{m}_{\mathrm{f}}$ Massa Final \\
\hline & $\begin{array}{c}\mathrm{m}_{\mathrm{b}} \text { Número de mols } \\
\text { (Base) }\end{array}$ & & \multirow{2}{*}{$\begin{array}{l}\text { V Volume da } \\
\text { Solução (L) }\end{array}$} & & \multirow{2}{*}{$\begin{array}{c}m_{r} \text { Massa que } \\
\text { reagiu }\end{array}$} \\
\hline & $\mathbf{v}_{\mathrm{b}}$ Volume (Base) & & & & \\
\hline
\end{tabular}

Fonte: Salatine (2011)

As reações químicas envolvidas para os cálculos são apresentadas nas reações (A), (B) e (C) abaixo. Para cálculo de massa inicial, a reação $(A)$ entre hidróxido de sódio e ácido clorídrico, a reação é de 1:1. Para formação da solução utilizada na titulação, as reações (B) e (C), sendo a reação do formaldeído com peróxido de hidrogênio e a reação do ácido fórmico com hidróxido de sódio, respectivamente (SALATINE, 2011). 


$$
\begin{gathered}
\mathrm{NaOH}+\mathrm{HCl} \rightleftharpoons \mathrm{NaCl}+\mathrm{H}_{2} \mathrm{O} \\
\mathrm{HCHO}+\mathrm{H}_{2} \mathrm{O}_{2} \rightleftharpoons \mathrm{HCOOH}+\mathrm{H}_{2} \mathrm{O} \\
\mathrm{HCOOH}+\mathrm{NaOH} \rightleftharpoons \mathrm{HCOONa}+\mathrm{H}_{2} \mathrm{O}
\end{gathered}
$$

\subsection{ETAPA 3: COMPARAÇ̃̃O DOS RESULTADOS COM A LEGISLAÇ̃̃O E COM A LITERATURA}

Com a obtenção dos resultados após as duas análises descritas acima, foi possível identificar a concentração de formaldeído livre nas amostras, comparar com a legislação vigente da ANVISA, Resolução da Diretoria Colegiada (RDC) 15, de 2013 e com os demais trabalhos publicados na área.

\section{RESULTADOSE DISCUSSÃO}

\section{Etapa 1: Coleta das amostras e caracterização}

Os resultados da análise da composição nas seis amostras de alisantes capilares, estão apresentadas no Quadro 2. Apenas a amostra 5, apresentou o componente "formaldeído" nos ingredientes.

Quadro 2 - Composição das amostras

\begin{tabular}{|c|c|}
\hline Amostra 1 & $\begin{array}{c}\text { Ingredientes } \\
\text { Água, ácido glioxílico, álcool cetoestearílico, sódio PCA, miristato de isopropil, trealose, } \\
\text { álcool cetoestearílico etoxilado, quaternário de amônio, glicerina, silicone(1), organic } \\
\text { tilicine, palmitato de cetila, óleo de coco babuçú, essência, jaguar C 13 S, silicone(2), } \\
\text { hidroxitolueno butilado, limoneno. }\end{array}$ \\
\hline Amostra 2 & $\begin{array}{c}\text { Água, propilenoglicol, quaternário de amônio, metilparabeno, propilparabeno, ácido cítri- } \\
\text { co, EDTA dissódico, hidroxitolueno butilado, álcool cetoestearílico, óleo mineral, dimethi- } \\
\text { cona, óleo de amêndoas, poliquaternário-10, poliquaternário-55, essência, surfactante(3). }\end{array}$ \\
\hline Amostra 3 & $\begin{array}{c}\text { Água, álcool cetoestearílico, quaternário de amônio, álcool cetoestearílico etoxilado, } \\
\text { glicerina, óleo de trigo, silicone(1), óleo de coco babuçú, essência, cisteína, arginina, } \\
\text { ácido cítrico, silicone(4), ceramida, hidroxitolueno butilado, polietilenoglicol, queratina } \\
\text { hidrolisada, palmitado de cetila, conservante, ácido glutâmico, ácido lático. }\end{array}$ \\
\hline Amostra 4 & $\begin{array}{c}\text { Água, bio.elixir(5), ácido acético, óleo de argan, bio restore(6), arginina, extrato de aveia, } \\
\text { hidroxitolueno butilado, álcool cetoestearílico etolixado, ácido acético, ácido lático, } \\
\text { quaternário de amônio, álcool cetilíco, alcohol, dimeticona, óleo de ojon, proteína de } \\
\text { trigo hidrolisada, proténa de quinoa, proteína de arroz, conservante, essência, poliqua- } \\
\text { ternio-7, prolina, lactato de sódio, sódio PCA, EDTA tetrasódio, valina. }\end{array}$ \\
\hline
\end{tabular}




\begin{tabular}{|c|c|}
\hline & Ingredientes \\
\hline Amostra 5 & $\begin{array}{c}\text { Água, álcool cetoestearílico, álcool cetoestearílico etoxilado, metasulfato de berrenil- } \\
\text { trimônio, quaternário de amônio, hidroxitolueno butilado, parafina líquida, lanolina, } \\
\text { glicerina, EDTA disódico, queratina hidrolisada, poliquaternário-10, essência, manteiga } \\
\text { de karité, extrato de trigo, proteína de soja hidrolisada, DNA hidrolisado, cisteína, for- } \\
\text { maldeído, ácido cítrico, conservante. }\end{array}$ \\
\hline Amostra 6 & Rótulo não foi cedido. \\
\hline
\end{tabular}

(1) - (6) ingredientes em blend:

(1) amodimethicone, cetrimonium chloride, trideceth-12

(2) silicone quaternium-16/glycidoxy dimethicone crosspolymer, C11-15 pareth-7, laureth-9, undeceth-11, undeceth-5

(3) quaternium-10, propylene glycol

${ }^{(4)}$ cyclopentasiloxane, dimethiconol, dimethicone crosspolymer

(5) aloe barbadensis leaf extract, camellia sinensis leaf extract, cinnamomum zeylanicum bark extract, acorus calamus root extract, commiphora myrrha resin extract, olea europaea (olive) fruit oil, argania spinosa kernel oil, polyglyceryl-3 diisostearate, glicerina, glyceryl stearate

(6) hydrolyzed wheat protein, methicone, polyquaternium-10, carbocysteine.

Fonte: Dados da pesquisa

Além da avaliação do rótulo, utilizou-se o número de processo para consulta da situação do alisante capilar no site da ANVISA. As amostras 3,4,5 possuem processos notificados ativos na ANVISA. A amostra 1 não possui processo e a amostra 6 não foi possível a identificação, já que a rotulagem não foi cedida.

Em relação à caracterização das amostras quanto ao $\mathrm{pH}$, ambos produtos não apresentavam informações na embalagem. Na Tabela 1, observa-se os resultados nas 6 amostras analisadas.

Tabela 1 - Resultado da determinação do pH nos alisantes capilares

Alisantes Capilares

Amostra 1

Amostra 2

Amostra 3

Amostra 4

Amostra 5

Amostra 6
Valor de pH

\section{3,33}

1,15

1,25

0,93

2,30

1,08

Fonte: Dados da pesquisa 
$\mathrm{O}$ uso do valor de $\mathrm{pH}$ nas rotulagens de produtos cosméticos, tem por finalidade a chamada de marketing, informação essa que não é obrigatória pela ANVISA, mas que agrega na hora de comprar. Associado ao uso negligente do formol, o pH dos alisantes pode sofrer alteração. Delfini (2011), ressalta que o pH ideal para os alisantes varia entre 5,0 e 6,5, sendo necessário que o pH esteja ácido para que ocorra o selamento das cutículas dos fios, mantendo-os hidratados, já que o pH alcalino abre as cutículas e deixa o cabelo poroso e frágil.

Formulações capilares com variações extremas de pH podem danificar o fio capilar, isso porque o cabelo encolhe e enrijece ou até mesmo dissolve por completo em $\mathrm{pH}$ muito ácido ou aumenta a porosidade à medida que as camadas de cutícula se dilatam, obtendo uma aparência ressecada e opaca, chegando até a dissolução completa do fio em pH fortemente alcalino. (REVISTA NEWS, 2018, ON-LINE).

\section{Etapa 2: Teor de formaldeído nas amostras}

Após a reação entre as amostras de alisantes capilares e o reagente de Schiff previamente preparado, cinco amostras apresentaram coloração rosa/malva das seis analisadas. Mediante a degradação do Reagente de Schiff, a cor rosa é observada. Quando uma amostra possui alto teor de formaldeído em sua composição, geralmente o produto tem formação de uma cor roxa (MARTINS et al., 2017).

Conforme a Figura 3, as amostras 3 e 4 apresentaram valor de teor mais elevado que as demais amostras, apresentando coloração rosa após a combinação com o Reagente de Schiff, onde o parâmetro visual pode ter sido alterado por algum outro componente presente na formulação do alisante capilar.

Figura 3 - Reação dos alisantes capilares após processo com o Reagente de Schiff

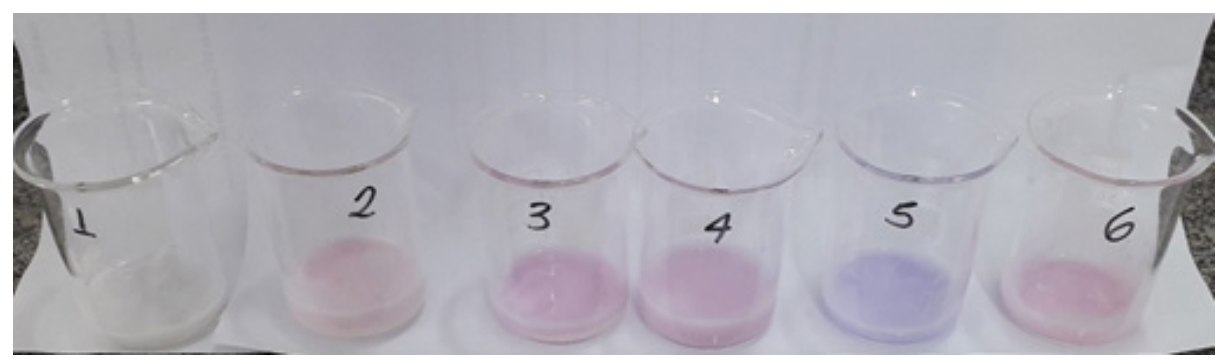

Fonte: Dados da pesquisa

Realizou-se o método titulométrico em triplicata, nas cinco amostras de alisantes capilares que indicaram coloração rosa a malva no teste do reagente de Schiff. As cinco amostras foram identificadas como amostras 2, 3, 4, 5, 6, sendo realizadas em triplicata. A média do volume gasto e o desvio padrão encontram-se na Tabela 3.

Para todas as amostras utilizou-se a mesma sequência de cálculos, apresentados na Figura 2. Os resultados dos cálculos I, II, III apresentam-se abaixo na Tabela 2. 
Tabela 2 - Resultados das equações I,II,III - Média e Desvio Padrão

\section{Média do volume} gasto $\mathrm{HCl}$

\section{Desvio Padrão}

$$
m_{b}
$$

m

$m_{r}$

\begin{tabular}{llllll}
\hline Amostra 2 & 1,07 & 0,094 & 0,107 mols & $0,0428 \mathrm{~g}$ & $1,95 \mathrm{~g}$ \\
Amostra 3 & 0,63 & 0,047 & 0,063 mols & $0,0252 \mathrm{~g}$ & $1,48 \mathrm{~g}$ \\
Amostra 4 & 0,63 & 0,047 & 0,063 mols & $0,0252 \mathrm{~g}$ & $1,48 \mathrm{~g}$ \\
Amostra 5 & 1,00 & 0,081 & 0,100 mols & $0,0400 \mathrm{~g}$ & $1,47 \mathrm{~g}$ \\
Amostra 6 & 0,73 & 0,047 & 0,073 mols & $0,0292 \mathrm{~g}$ & $1,47 \mathrm{~g}$ \\
\hline
\end{tabular}

Fonte: Dados da pesquisa

Segundo a reação $(\mathrm{C})-\mathrm{HCOOH}+\mathrm{NaOH} H C O O N a+H 2 O$, a proporção é de 1:1 entre hidróxido de sódio que reage com ácido fórmico, formando água e formiato de sódio, ocorrido na oxidação do formaldeído.

Nos cálculos (Material Suplementar), verificou-se o teor de formaldeído nas amostras positivas para o reagente de Schiff. No primeiro cálculo determinou-se a quantidade de metanal que reagiu com a massa do hidróxido de sódio, utilizando o resultado da equação (III) e, em seguida, calculou-se a porcentagem de formaldeído presente nas amostras. A Figura 4 apresenta os resultados do teor de formaldeído calculado em cada uma das amostras.

Figura 4 - Teor de Formaldeído por amostra

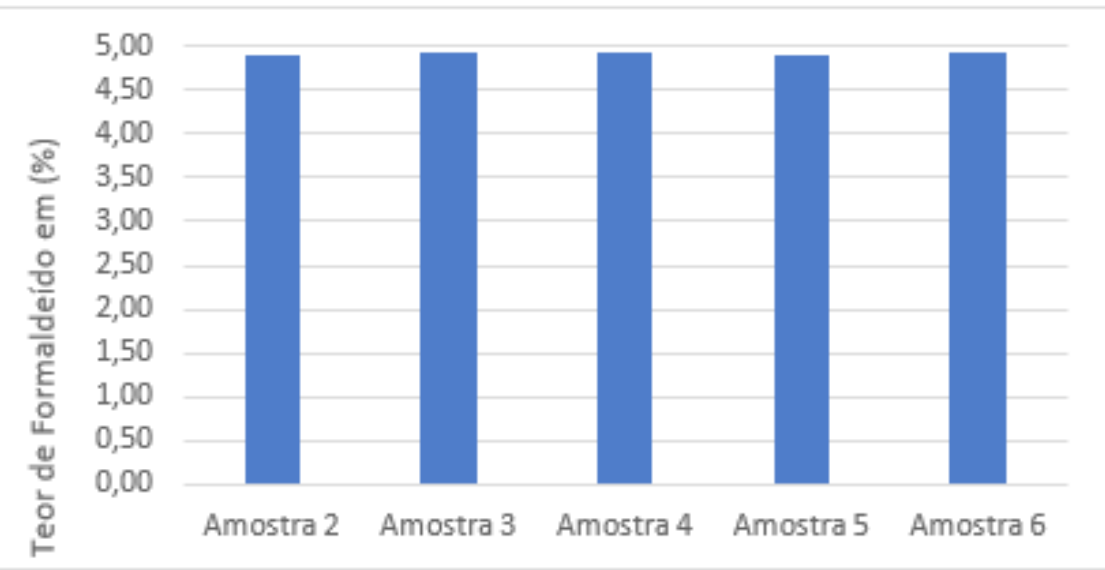

Fonte: Dados da pesquisa

A Tabela 3 apresenta uma comparação dos resultados encontrados no presente trabalho com outras literaturas, sendo eles pelo método instrumental de Titulação e Espectrofotometria. 
Tabela 3 - Comparação dos resultados obtidos com demais literaturas

\begin{tabular}{|c|c|c|}
\hline $\begin{array}{l}\text { Concentração de } \\
\text { Formaldeído }\end{array}$ & Observação & Referência \\
\hline $4,89-4,93 \%$ & $\begin{array}{l}\text { Foram analisadas } 5 \text { amostras de alisantes capilares. Utilizou- } \\
\text {-se o método da análise titulométrica para o cálculo do teor de } \\
\text { formaldeído. }\end{array}$ & $\begin{array}{l}\text { Presente } \\
\text { Trabalho }\end{array}$ \\
\hline $0,05-4,17 \%$ & $\begin{array}{l}\text { Foram analisadas } 28 \text { amostras de alisantes capilares. Utilizou-se } \\
\text { o método de análise por espectrofotometria para o cálculo do } \\
\text { teor de formaldeído. }\end{array}$ & $\begin{array}{l}\text { Vitola et al. } \\
\text { (2019) }\end{array}$ \\
\hline $0,012-9,11 \%$ & $\begin{array}{l}\text { Foram analisadas } 13 \text { amostras de alisantes capilares. Utilizou-se } \\
\text { o método de análise por espectrofotometria para o cálculo do } \\
\text { teor de formaldeído. }\end{array}$ & $\begin{array}{l}\text { Moro et al. } \\
\quad(2015)\end{array}$ \\
\hline $0,04-18,5 \%$ & $\begin{array}{l}\text { Foram analisadas } 10 \text { amostras de alisantes capilares. Utilizou-se } \\
\text { o método de análise por espectrofotometria para o cálculo do } \\
\text { teor de formaldeído. }\end{array}$ & $\begin{array}{l}\text { Crippa et al. } \\
\quad(2015)\end{array}$ \\
\hline $2,51-4,73 \%$ & $\begin{array}{l}\text { Foram analisadas } 4 \text { amostras de alisantes capilares. Utilizou- } \\
\text {-se o método da análise titulométrica para o cálculo do teor de } \\
\text { formaldeído. }\end{array}$ & $\begin{array}{l}\text { Silva et al. } \\
\text { (2019) }\end{array}$ \\
\hline $2,48-4,70 \%$ & $\begin{array}{l}\text { Foram analisadas } 4 \text { amostras de alisantes capilares. Utilizou-se o } \\
\text { método de análise por espectrofotometria para o cálculo do teor } \\
\text { de formaldeído. }\end{array}$ & $\begin{array}{l}\text { Silva et al. } \\
\text { (2019) }\end{array}$ \\
\hline $4,58-4,61 \%$ & $\begin{array}{l}\text { Foram analisadas } 3 \text { amostras de alisantes capilares. Utilizou- } \\
\text {-se o método da análise titulométrica para o cálculo do teor de } \\
\text { formaldeído. }\end{array}$ & Salatine (2011) \\
\hline $0,00-3,83 \%$ & $\begin{array}{l}\text { Foram analisadas } 8 \text { amostras de alisantes capilares. Utilizou-se o } \\
\text { método de análise por espectrofotometria para o cálculo do teor } \\
\text { de formaldeído. }\end{array}$ & $\begin{array}{l}\text { Abreu et al. } \\
\text { (2015) }\end{array}$ \\
\hline
\end{tabular}

Fonte: Dados da pesquisa

De acordo com a tabela 3, todas as literaturas observadas apresentaram um índice com mais de $70 \%$ das amostras analisadas com valores altos de formaldeído em sua composição. Os resultados obtidos no presente trabalho apresentaram-se muito semelhante aos demais resultados das literaturas utilizadas para construção do comparativo.

Silva e colaboradores (2019), indicam elevadas concentrações de formol nas amostras de alisantes capilares, determinadas a partir da absorbância e quando comparado ao método titulométrico os valores enquadram-se dentro do proposto. Assim, as duas técnicas apresentam-se eficazes para o cálculo do teor de formaldeído no trabalho. Segundo Crippa e colaboradores (2015), nos resultados obtidos observou-se que mesmo com as legislações vigentes que limitam a utilização de 
formaldeído em produtos cosméticos, seu uso irregular em alisantes capilares ainda persiste e em teor muito acima do permitido.

Abreu e colaboradores (2015) descrevem que além do doseamento, também é importante analisar as características organolépticas e físico-químicas de uma formulação cosmética, pois geralmente, a textura, odor, cor e aspecto do produto são examinados antes da sua compra, sendo parâmetros importantes do ponto de vista comercial, uma vez que o consumidor pode ou não ser atraído por essas características.

Méndez (2000) realizou um estudo com 66 pessoas com exposição crônica ao formaldeído e observou que, em tempo de exposição de 8 a 72 horas por semana, foram frequentes os relatos de irritação e obstrução nasal, dor de garganta, tosse seca, dispneia, dor de cabeça, fadiga, diminuição da memória recente, irritação nos olhos e lacrimejamento, além de distúrbios dermatológicos como urticária, bolhas e dermatite, demonstrando que exposições a altas concentrações de formaldeído podem provocar reações adversas significantes. Assim, ressalta-se a importância do controle e identificação deste composto por parte da legislação.

\section{CONCLUSÃO}

0 presente trabalho teve como objetivo avaliar alisantes capilares de diferentes marcas para verificação do teor de formaldeído livre em seus ingredientes, avaliação de rótulo e comparação com demais trabalhos já publicados.

De acordo com os resultados do estudo, das seis amostras recolhidas, cinco apresentaram valores superiores a $0,01 \%$, com uma média de $4,914 \%$ de formaldeído livre em sua composição. Identificou-se que os produtos que contêm a proposta de alisamento da fibra capilar, necessitam de um controle maior e especial quanto ao ingrediente utilizado para a função "alisante”. Principalmente o formaldeído, substância essa que está sendo utilizada em altos níveis, levando o usuário e profissional a problemas de saúde imediatos e a longo prazo.

Os resultados mostraram-se efetivos por meio das análises, deixando claro que existe a necessidade de uma fiscalização mais branda por parte dos órgãos fiscalizadores para a liberação dos produtos cosméticos antes de serem comercializados. 0 estudo realizado limita-se somente às amostras que foram coletadas na região metropolitana, RS.

Assim, este trabalho teve como objetivo despertar discussões sobre o tema e abordar legislações do uso do formaldeído. Estudos futuros são necessários visando analisar um maior número de amostras e comparar diferentes métodos instrumentais de análise, como a espectrofotometria.

\section{REFERÊNCIAS}

ANVISA. Agência Nacional de Vigilância Sanitária. Guia de controle de qualidade de produtos cosméticos. 2. ed. Brasília: Anvisa/MS, 2007a. 
ANVISA. Agência Nacional de Vigilância Sanitária. Cartilha sobre alisantes: orientações quanto ao uso correto, cuidados e precauções necessárias. Informações gerais mais relevantes. Brasília: Anvisa/MS, 2007b. Disponível em: http:// anvisa.gov.br/cosmeticos/alisantes/folder. Acesso em: 18 de novembro de 2019

ANVISA. Agência Nacional de Vigilância Sanitária. Resolução da Diretoria Colegiada RDC N 15, de 26 de março de 2013. Brasília: Anvisa/MS, 2013. Disponível em: http://bvsms.saude.gov.br/bvs/ saudelegis/anvisa/2013/rdc0015_26_03_2013.pdf. Acesso em: 13 jul. 2019.

ABREU, V. M. et al. Cosmetovigilância em alisantes capilares: Determinação do teor de formaldeído por espectrofotometria e avaliação do rótulo. J. Basic Appl. Pharmaceut. Sci., v. 36, n. 1, p. 51-58 2015.

CRIPPA, V. O. et al. Análise quali-quantitativa de formaldeído em amostras de produtos destinados ao alisamento capilar utilizados em salões de beleza no município de Linhares, ES-Brasil. Infarma Ciên. Farmacêut., v. 27, n. 1, p. 22-27, 2015.

DELFINI, F. N. A. Ativos alisantes em cosméticos. 2011. 53 f. Trabalho de Conclusão de Curso (Farmácia-Bioquímica) - Universidade Estadual Paulista, Araraquara, 2011. Disponível em: http:// hdl.handle.net/11449/118857. Acesso em: 15 jul. 2020.

INCA - Instituto Nacional do Câncer. Formol. Rio de Janeiro: INCA, 2018. Disponível em: https:// www.inca.gov.br/exposicao-no-trabalho-e-no-ambiente/solventes/formol. Acesso em: 12 jun. 2019.

MARTINS, G. B. C. et al. Papel indicador colorimétrico para detecção de formol em produtos lácteos e produtos de higiene pessoal. Quim. Nova, v. 40, n. 8, p. 946-951, 2017.

MÉNDEZ, T. R. Efectos tóxicos crónicos del formaldehido. MedULA Rev. Facult. Med., v. 9, n. 1, p. 9, 2000.

MORO, J. et al. Avaliação qualitativa e quantitativa de formaldeído em produtos cosméticos para alisamento capilar. J. Basic Appl. Pharmaceut. Sci., v. 36, n. 4, 2015.

REVISTA NEWS. Saúde. Formol acima do permitido em produtos avaliados pela PROTESTE, 2018. Disponível em: https://revistanews.com.br/2018/06/08/formol-acima-do-permitido-em-produtosavaliados-pela-proteste/. Acesso em: 2 nov. 2019.

SALATINE, A. P. Doseamento de formaldeído em produtos capilares. 2011. 64 f. Trabalho de Conclusão de Curso (Química Industrial) - Instituto Municipal de Ensino Superior de Assis. Assis, 2011. Disponível em: https://cepein.femanet.com.br/BDigital/arqTccs/0711290582.pdf. Acesso em: 3 ago. 2019. 
SCARABELOT, J. F.; MICHELS, M. L. Validação de metodologia para análise e investigação de Programa de iniciação cientifica formol em amostras de produtos usados em alisamento de cabelo. Programa Unisul de Iniciação Científica, 2007. Anais [...], Tubarão-SC, 2007.

SILVA, N. C. S. et al. Análise da presença de formol em produtos para alisamento capilar. Única Cad. Acad., v. 2, n. 1, p. 1-4, 2019.

VITOLA, J. F. et al. Avaliação do teor de formaldeído em amostras de alisantes capilares utilizados em salões de beleza de Pedro Gomes, MS, Brasil. Infarma Ciên. Farmacêut., v. 31, n. 1, p. 28-33, 2019.

WEATHERSBY, C; MCMICHAEL, A. Brazilian keratin hair treatment: a review. J. Cosmet. Dermatol., v. 12, n. 2, p. 144-148, 2013. 
1 Química pela Universidade La Salle, Canoas-RS.

E-mail: abiarodriguess@gmail.com

2 Doutora em Engenharia Química; Professora do Programa de Pós-Graduação em Avaliação de Impactos Ambientais da Universidade La Salle, Canoas-RS.

E-mail: fernanda.souza@unilasalle.edu.br

3 Doutora em Engenharia Química; Professora na Universidade La Salle, Canoas-RS.

E-mail: janice.hamm@unilasalle.edu.b

\section{(2) (1) ( )}

Este artigo é licenciado na modalidade acesso abertosob a Atribuição-Compartilhalgual CC BY-SA

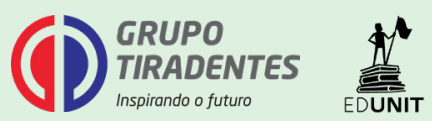

